\title{
Aggregate JTCB Interval
}

National Cancer Institute

\section{Source}

National Cancer Institute. Aggregate JT CB Interval. NCI Thesaurus. Code C117763.

A JTAG interval corrected for heart rate using Bazett's formula. (CDISC) 